\title{
NBSIR $75-827$
}

\section{REPORT ON NBS DUAL MIXER TIME DIFFERENCE SYSTEM (DMTD) BULLT FOR TIME-DOMAIN MEASUREMENTS ASSOCIATED WITH PHASE 1 OF GPS}

David W. Allan

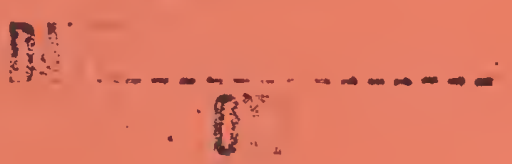

Time and Frequency Division Institute for Basic Standards National Bureau of Standards Boulder, Colorado 80302 



\section{REPORT ON NBS DUAL MIXER TIME DIFFERENCE SYSTEM (DMTD) BUILT FOR TIME-DOMAIN MEASUREMENTS ASSOCIATED WITH PHASE 1 OF GPS}

David W. Allan

Time and Frequency Division Institute for Basic Standards National Bureau of Standards Boulder, Colorado 80302

January 1976

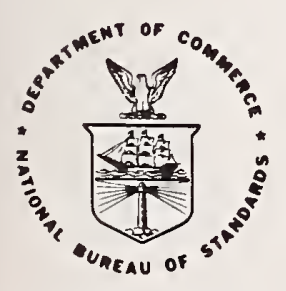

U.S. DEPARTMENT OF COMMERCE, Rogers C. B. Morton, Secretary James A. Baker, III, Under Secretary Dr. Betsy Ancker-Johnson, Assistant Secretary for Science and Technology 



\author{
David W. Allan
}

\begin{abstract}
Based on a previous work reported at the 1975 Frequency Control Symposium, the National Bureau of Standards was asked to build a Dual Mixer Time Difference (DMTD) measuring system. This report includes the design, construction, and testing of this DMTD system in fulfillment of this request. The precision of time difference measurement with this system was shown to be about 0.1 picosecond and the accuracy about $10 \mathrm{ps}$; similarly, the frequency stability precision was shown to be described by $\sigma_{y}(\tau) \simeq 10^{-13} \tau^{-1}, 0.1 \mathrm{~s}<\tau<10^{3} \mathrm{~s}$ and equal to $10^{-16}$ at $\tau$ equal about half a day.

The request for this DMTD system was for measuring the clocks that will go on board the satellites for Phase I of the Global Positioning System (GPS) program. The DMTD system described in this report is the only system that can easily meet all of the time-domain measurement requirements for this program.
\end{abstract}

KEY WORDS: Frequency measurement; Frequency mixing; Global Positioning System; Isolation amplifiers; Low-noise amplifiers; Precision frequency measurements; Precision time measurements; Time difference measurements; Time-domain frequency stability; Time interval.

Having gained additional insights from the prototype DMTD system reported on at the 1975 Frequency Control Symposium we made appropriate changes in designing and building a DMTD system to fulfill a request for a time-domain measuring system to be used in Phase I of GPS. These included: a pair of NBS designed isolation amplifiers for splitting the signal from the common oscillator, the signal from the common oscillator is fed through isolation transformers to the isolation amplifiers; an improved low-pass filter following each mixer; an additional and lower noise stage of amplification following each low-pass filter, better bandwidth control included in the 2nd stage of amplification; a driver to feed each pulse isolation transformer for an improved pulse shape; the ability to use or not use the phase shifter in one leg of the system; both electric and magnetic shielding properly displaced to reduce capacitive coupling, and non-battery operation using well isolated, regulated, and decoupled DC power supplies.

A local subcontractor was sought and obtained to do the layout, assembly, and overall construction.

Attached are the block and circuit diagrams of the DMTD system as prepared by the subcontractor (No. 75008-A] through 75008-A6). The phase shifter in $A-1$ has $\sim 100 \Omega$ input impedance and $10 \mathrm{~dB}$ insertion loss. The inputs to the mixers, should not exceed $\sim 3 \mathrm{~mW}$. The low-pass filter (LPF) has a roll-off at about $10 \mathrm{kHz}$. The bandwidths $f_{h}$ of the amplifiers are ganged and discretely variable $(1,3,10,30,100,300,1000 \mathrm{~Hz})$. The isolated output pulses corresponding with the zero crossings of the beat frequency have about 4 volts output into a high impedance with 20 ns rise time. On sheet 1 of A-2 test point 1 (TP-1) should read $\sim 600 \mathrm{mV}$ peak-to-peak for near optimum signal-to-noise performance out of the mixers. The common oscillator input shown in A-4 should not exceed $\sim 1 \mathrm{~mW}(0.6 \mathrm{~V}$ peak-to-peak at input of isolation amplifiers A-5); the amplifier will distort at higher drive levels. 
II. Testing and Measurement of DMTD System Noise

A $10.23 \mathrm{MHz}$ quartz crystal oscillator lent to NBS for testing was used to drive both mixer one and two to estimate the system noise. The oscillator output was insufficient to obtain optimum signal-to-noise conditions, but adequate for testing. The R-port of each mixer was driven with about 0.6 volt peak-to-peak and the L-port with about 0.36 volt peak-to-peak giving a mixer output of only $170 \mathrm{mV}$ peak-to-peak, i.e., the signal-to-noise could be about 3 or 4 times better with higher drive levels.

The common oscillator employed was a low-noise synthesizer. One can graphically see the effects of common oscillator noise by tuning the phase of the two beat signals to near zero. The attached sheet headed with the date 8 October 1975 page 1 is a copy of the lab notes during the testing. The left column of data are all taken with the bandwidth, $f_{h}$, set to $1 \mathrm{kHz}$ and the beat frequency at $10 \mathrm{~Hz}$-- giving a time difference measurement every $0.1 \mathrm{~s}$. The $\Delta t$ indicates the degree of synchronization of the phases of the beat signals, and it is obvious that as they are moved from near zero phase difference toward large phase difference the phase noise increases considerably. The right column shows the same effect only with a $10 \mathrm{~Hz}$ bandwidth.

The DMTD system noise was measured by setting the phase difference between the beat signals near zero to reduce the effects of common oscillator noise and then using a computing counter to measure the fractional frequency stability in terms of $\sigma_{y}(\tau)$ for various bandwidths and beat frequencies. These results are summarized in the attached $\sigma_{y}(\tau)$ vs $\tau$ diagram.Also shown on this diagram are some values translated from some data taken in the frequency domain. These data were obtained by removing both covers to the instrument so that a lead could be attached to test point 2 (TP-2 in drawing A-2) on mixer 1 and then later on mixer 2. A signal from the $10.23 \mathrm{MHz}$ test oscillator was fed into the mixer port through the phase shifter and also into the common oscillator port; the phase was shifted to obtain quadrature ( 0 volts out of the mixer). The signal from TP-2 was fed into a low-noise amplifier and into a spectrum analyzer to deduce the frequency domain stability $S_{\phi}(f)$ of the phase for this much of the circuit, which should be the critical noise contributor. The results using mixer 2 were essentially the same. Some $60 \mathrm{~Hz}$ sidebands were present at a level of $-116 \mathrm{~dB}$, but these apparently disappear when the shielding lids are put back, because such a level would give $\sigma_{y}(\tau=1 \mathrm{~s})=7 \times 10^{-12}$, but instead we obtain a 1 second stability better than 1 part in 10 13 , and with no apparent $60 \mathrm{~Hz}$ present when the beat frequency is set to that value in order to filter it out if it were present. Attached also is a sheet headed with the date 8 October 1975 page 2 which shows the time difference stability over a couple of minutes with $f_{h}=1 \mathrm{~Hz}$ and with a 1 second beat, $\nu_{b}=1 / \tau$. A slight phase drift is observed. A test was conducted from a cold start of the instrument to ascertain the long-term time difference stability of the unit. During the first hour it drifted $v 50$ ps and then in an overnight run the phase stayed within a peak-to-peak deviation of $\sim 10$ ps with ambient temperature fluctuations of about $\pm 2 \mathrm{C}^{\circ}$. This would correspond to a worst case one day sample time fractional frequency departure of about one part in $10^{16}$. 
III. Usage of the NBS DMTD Instrument

Attached are four sequential photographs of the instrument: 1) Front pane1; 2) Top view with electric shield cover removed; 3) Top view with electric and magnetic shield covers removed; and 4) close up of contents in magnetic shield compartment. The instrument is broadband ( $\sim 1 \mathrm{MHz}-60 \mathrm{MHz}$ ) except for the phase shifter which covers $\pm 1 \mathrm{MHz}$ about $10.23 \mathrm{MHz}$. One may conveniently choose whether or not to use the phase shifter. If used it provides a convenient method of setting the output time difference to any desired point, and if the common oscillator noise is excessive one can set the beats in phase ( $\Delta T \simeq 0$ ), so that one obtains a reduction of the noise contribution coming from the common oscillator. The phase shifter has the disadvantage that it has $\sim 10 \mathrm{~dB}$ insertion loss.

The mixer inputs go directly to the low noise Schotcky barrier diode double balanced mixers and optimally should be driven with about 1 to $3 \mathrm{~mW}$. CAUTION: excessive drive levels (maximum current $40 \mathrm{~mA}$ or about $2 \mathrm{~V}_{\mathrm{rms}}$ ) on the mixers will burn them out. About 1 volt peakto-peak input is a good operating point. The common oscillator port can be driven up to about 0.6 volts peak-to-peak $(\sim .3 \mathrm{~mW})$ before the isolation amplifiers, which feed the other ports of the mixers, start to distort.

The measurement bandwidth $f_{h}$ should always be greater than or equal to the beat frequency $\nu_{b}$. It is sometimes convenient to change the bandwidth and see its effect on the stability to get an idea of the kind of noise process that may be dominant. If the bandwidth is set too small, the stability determined will be too good for sample times less than $1 / f_{h}$.

The output pulses have about a $20 \mathrm{~ns}$ rise time and about 4 volts height into a high impedance. The steepest slope and ideal trigger point is a + slope at about +1 volt. The pulses will work into a $50 \Omega$ load with the amplitude and rise time degraded by about a factor of 2 . These output pulses are respectively tied to the phases of oscillator 1 and oscillator 2 , and the time difference $x(i)$ between the zero crossings of these two oscillators for the $i^{\text {th }}$ measurement is given by

$$
x(i)=\left(T_{1}-T_{2}\right) \quad \frac{\nu_{b}}{\nu_{0}}+\frac{\dot{\phi}}{2 \pi \nu_{0}}
$$

where $T_{1}-T_{2}=\Delta T$ is the actual time difference read on a time interval counter with $T_{1}$ connected to the start jack and $T_{2}$ to the stop jack, where $\phi$ is the total phase difference between the two halves of the dual mixer time difference system--most of which will be that due to the phase shifter, and where $\nu_{b}$ and $\nu_{0}$ are the nominal beat frequencies and carrier frequencies respectively. As an example suppose that $\Delta T=25.3 \mu \mathrm{s}$ for the $i^{\text {th }}$ measurement and $\nu_{b}=10 \mathrm{~Hz}$ and $\nu_{0}=10 \mathrm{MHz}$, then the time difference of osc 1 - osc $2=25.3 \mathrm{ps}$ $+\frac{\phi}{2 \pi \nu_{0}}$. Suppose, for the $(i+1)^{\text {th }}$ measurement, we get $25.6 \mathrm{ps}+\frac{\phi}{2 \pi \nu_{0}}$, which is $100 \mathrm{~ms}$ later, then the average fractional frequency difference over that interval is given by: 


$$
\begin{aligned}
y(i) & =\frac{x(i+1)-x(i)}{\tau} \\
& =\frac{0.3 \mathrm{ps}}{100 \mathrm{~ms}}=3 \times 10^{-12}
\end{aligned}
$$

The stability may be computed from the frequency or the time data as follows:

$$
\sigma_{y}{ }^{2}(\tau)=\frac{1}{2(M-1)} \sum_{i=1}^{M-1}[y(i+1)-y(i)]^{2}
$$

or

$$
\sigma_{y}{ }^{2}(\tau) \simeq \frac{1}{2(M-1) \tau^{2}} \sum_{i=1}^{M-1}[x(i+2)-2 x(i+1)+x(i)]^{2}
$$

where there are $M+1$ time readings in a sequence. If one wishes to take the square root and compute $\sigma_{y}(\tau)$ direct from the $\Delta T$ readings of a time interval counter then:

$$
\sigma_{y}(\tau) \simeq \frac{\nu_{b}}{\sqrt{2(M-1)} \cdot \tau \nu_{0}}\left\{\sum_{i=1}^{M-1}[\Delta T(i+2)-2 \Delta T(i+1)+\Delta T(i)]^{2}\right\}^{1 / 2}
$$

where $\tau$ (the interval between time difference measurements) can be any integer multiple of $1 / v_{b}$; i.e., one does not have to measure at every cycle of the beat frequency. Equation 5 can be approximately summarized for the measurement noise of the DMTD system as:

$$
\sigma_{y}(\tau) \simeq \frac{0.1 \text { ps }}{\tau}, 0.1 \mathrm{~s} \leqslant \tau \leqslant 10^{3} \mathrm{~s}
$$

with only a slight degradation for longer times due to apparent temperature induced phase drifts and for shorter times due to white noise as the bandwidth $f_{h}$ is opened up.

\section{Maintenance}

The unit should be free of need for any maintenance procedure. The 0P-05 operational amplifiers were DC balanced during the NBS testing phase, and their specifications of 3. $5 \mathrm{\mu V}$ per month should be low enough to give no difficulty in the foreseeable future unless the ultimate finesse is wanted from this DMTD instrument. These operational amplifiers are zeroed by simply grounding the input test point, and while monitoring the output test point of that operational amplifier adjusting the trim pot associated with it for zero volts $D C$ output. 


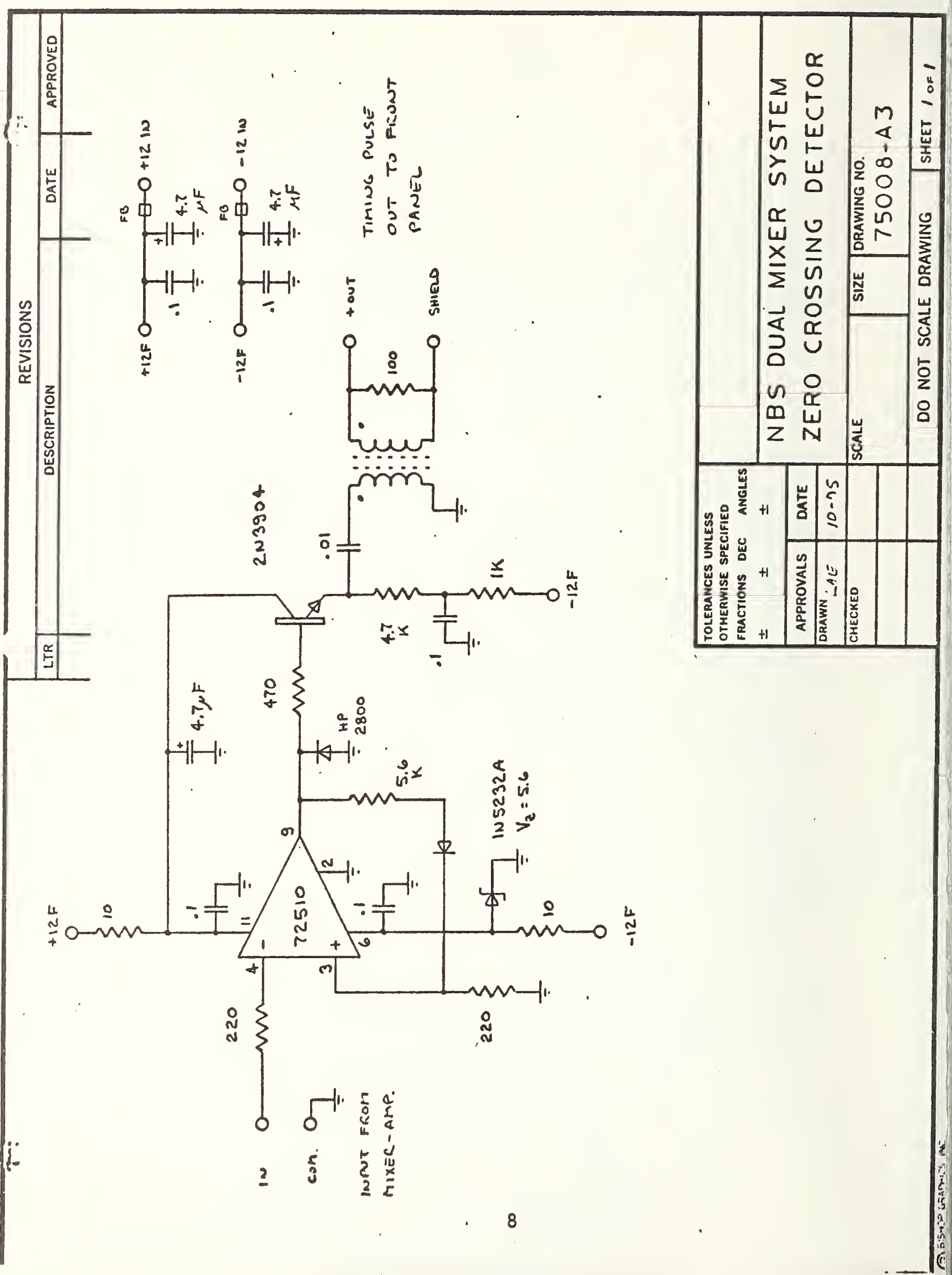




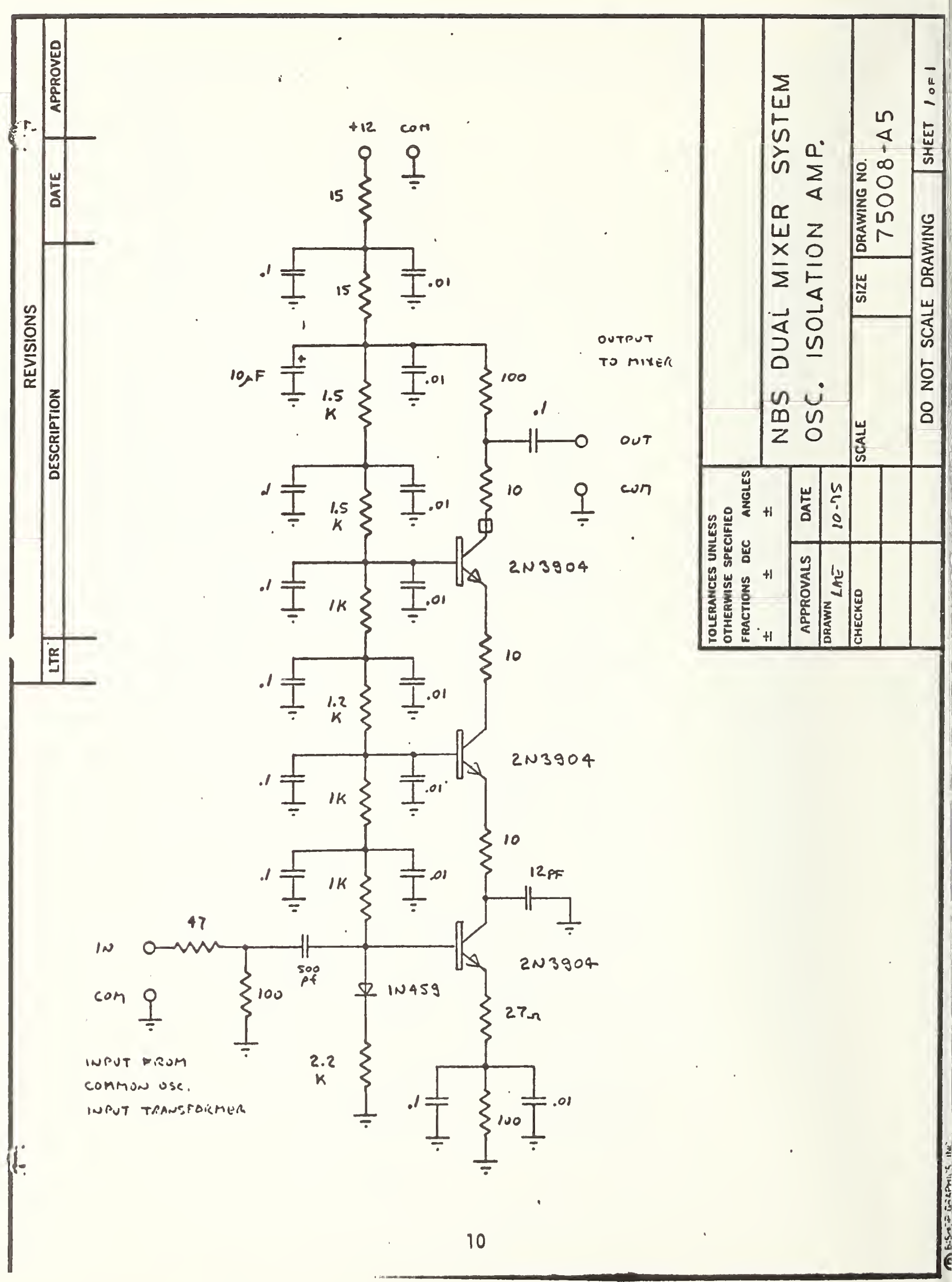




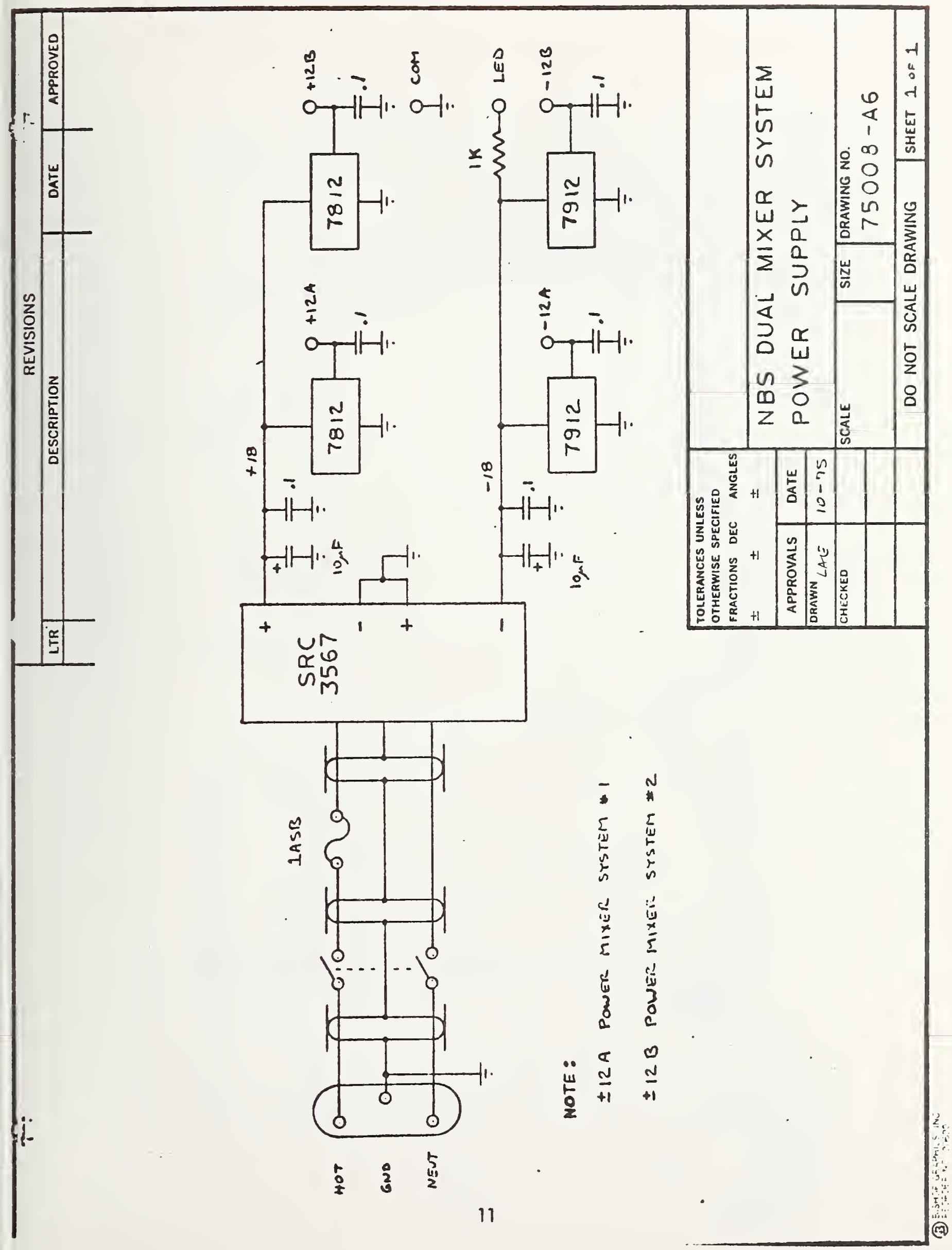




\section{October 75}

DMTD test of system noise as a function of common oscillator rejection 10.23 feed through $\phi$-shifter to mixer 1 and split before $\phi$-shifter to mixer 2 Same levels as yesterday. Set the beat $\nu_{b}=10 \mathrm{~Hz}$ $\therefore \tau=0.1 \mathrm{~s}$ and plotted the phase for various shifts or $\Delta t$ readings on counter. Chart speed $=10 \mathrm{~cm} / \mathrm{min}$ Sensitivity 1 ps per $\mathrm{cm}$
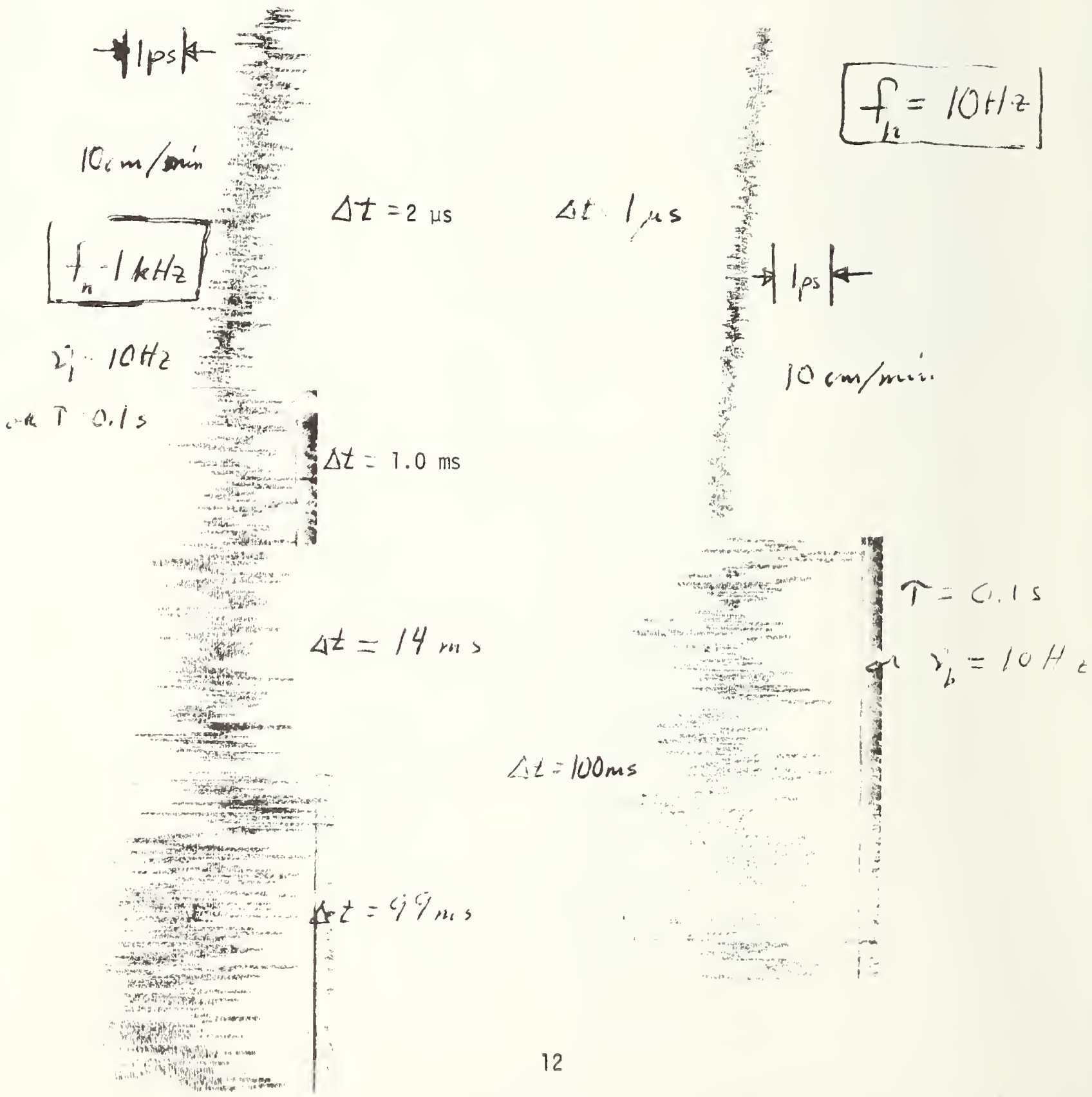
Same oscillator drive levels and condition as before. $\Delta t \sim$ few $\mu$ s to reduce common oscillator noise contribution to test measurement system noise and phase drift.

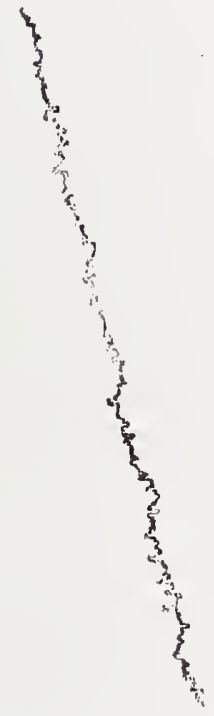

$\rightarrow 1 \mathrm{ps} \leftarrow$

$\tau=1 \mathrm{~s}$

$f_{h}=1 \mathrm{~Hz}$

$2.5 \mathrm{~cm} / \mathrm{min}$

Warm up phase drift was about 50 ps over the first hour; but stabilizing to a peak of about $10 \mathrm{ps}$ thereafter in an overnight run with $\pm 2^{\circ} \mathrm{C}$ ambient temperature fluctuations. 
㭊

严

岁

$\square$
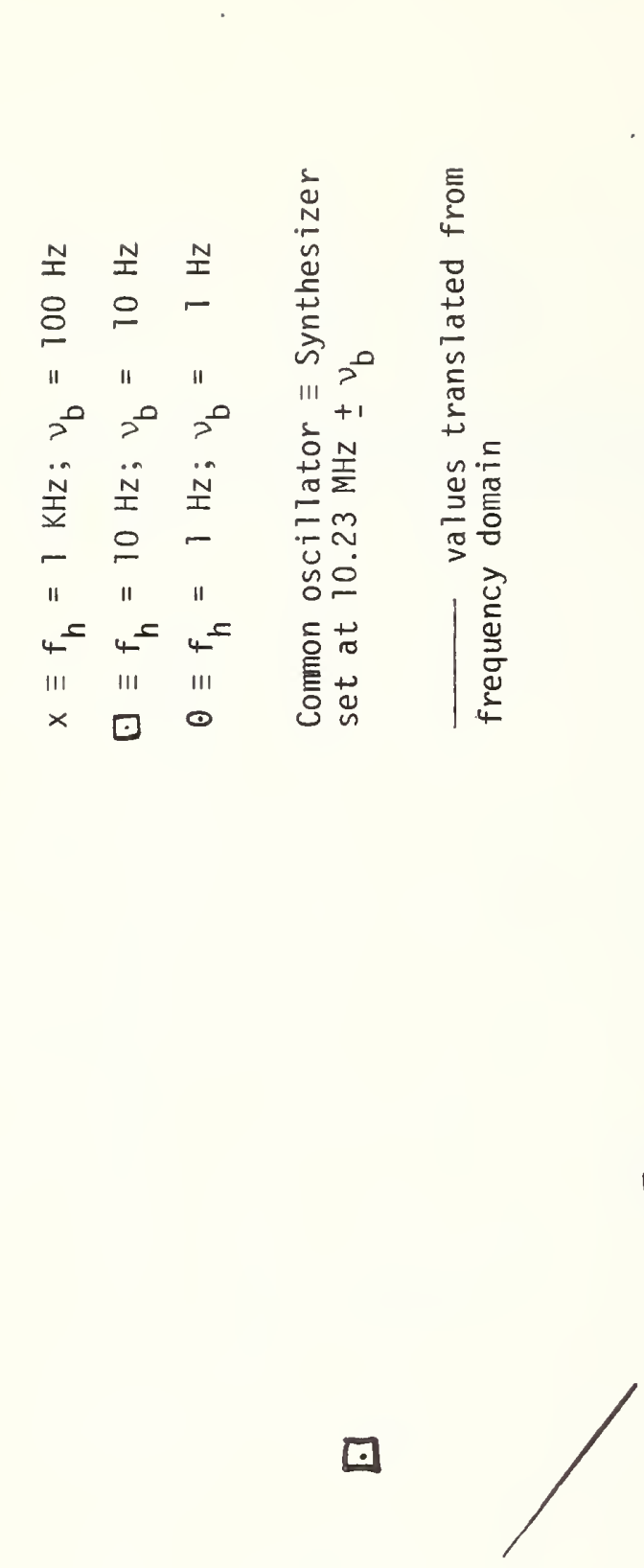

$\odot$

$\odot$

$\odot^{\circ}$

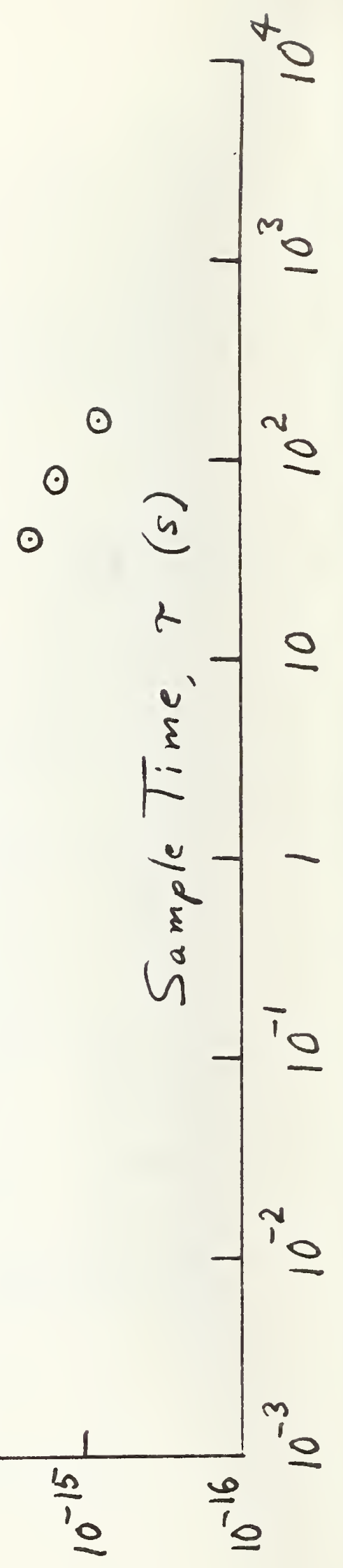




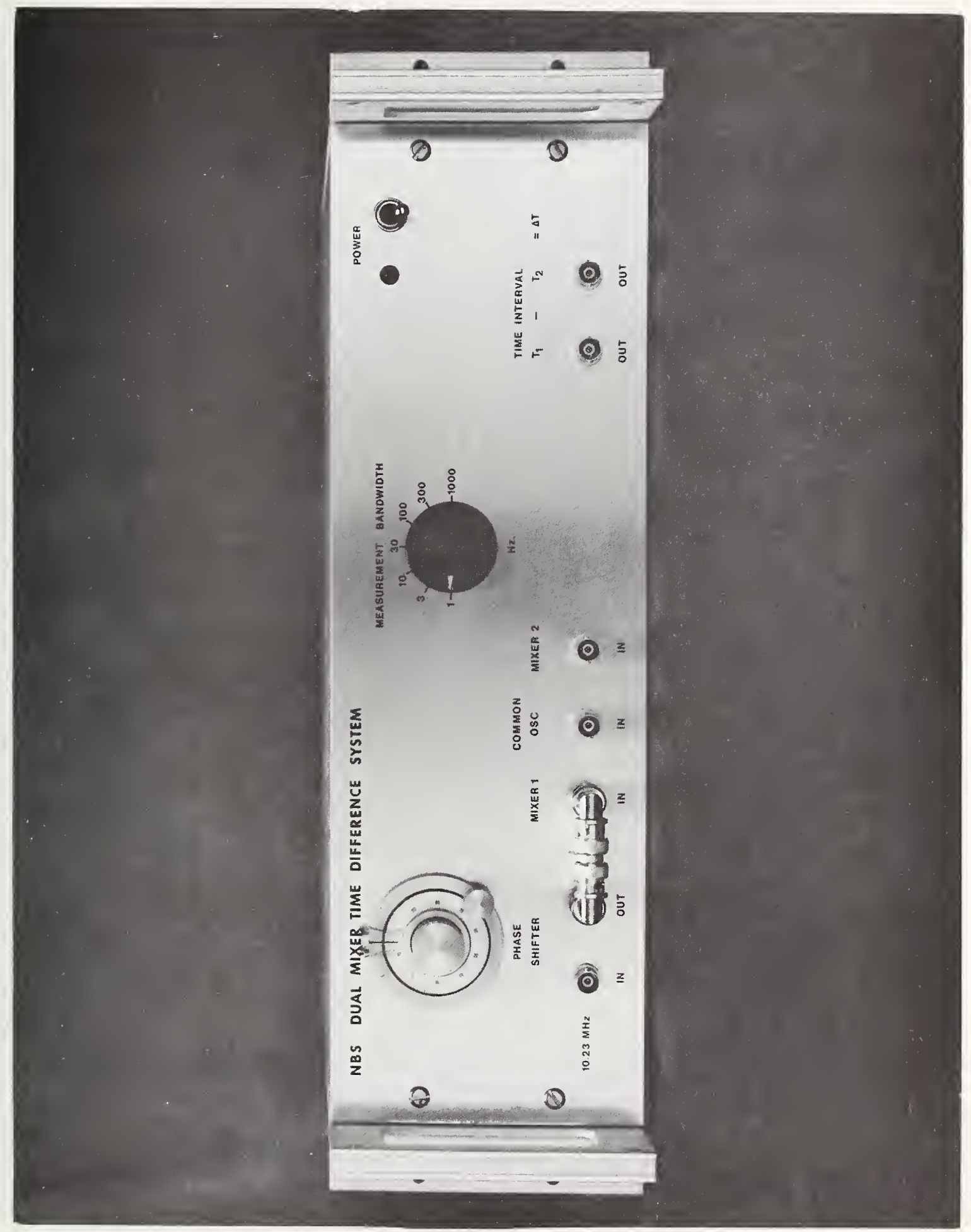




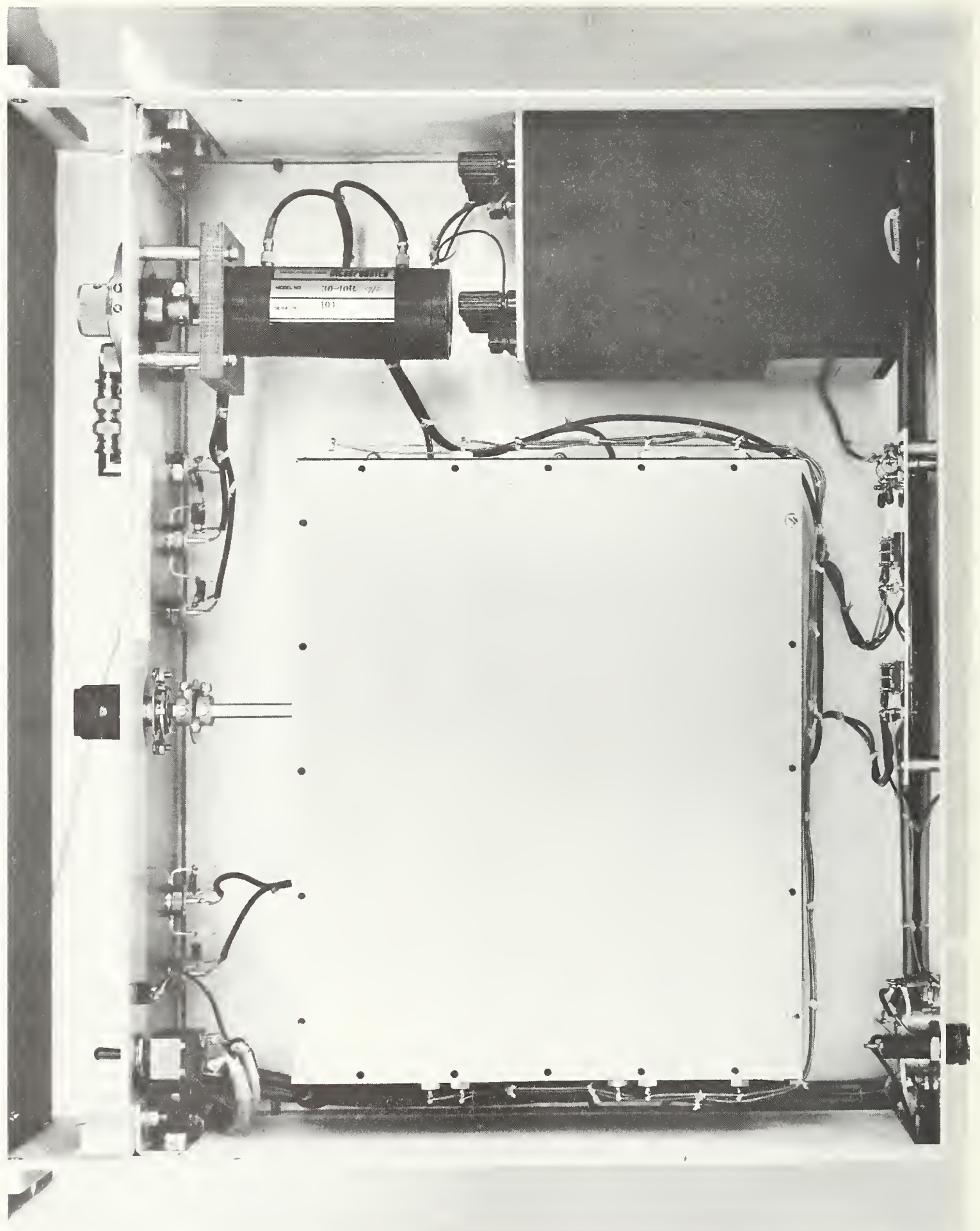




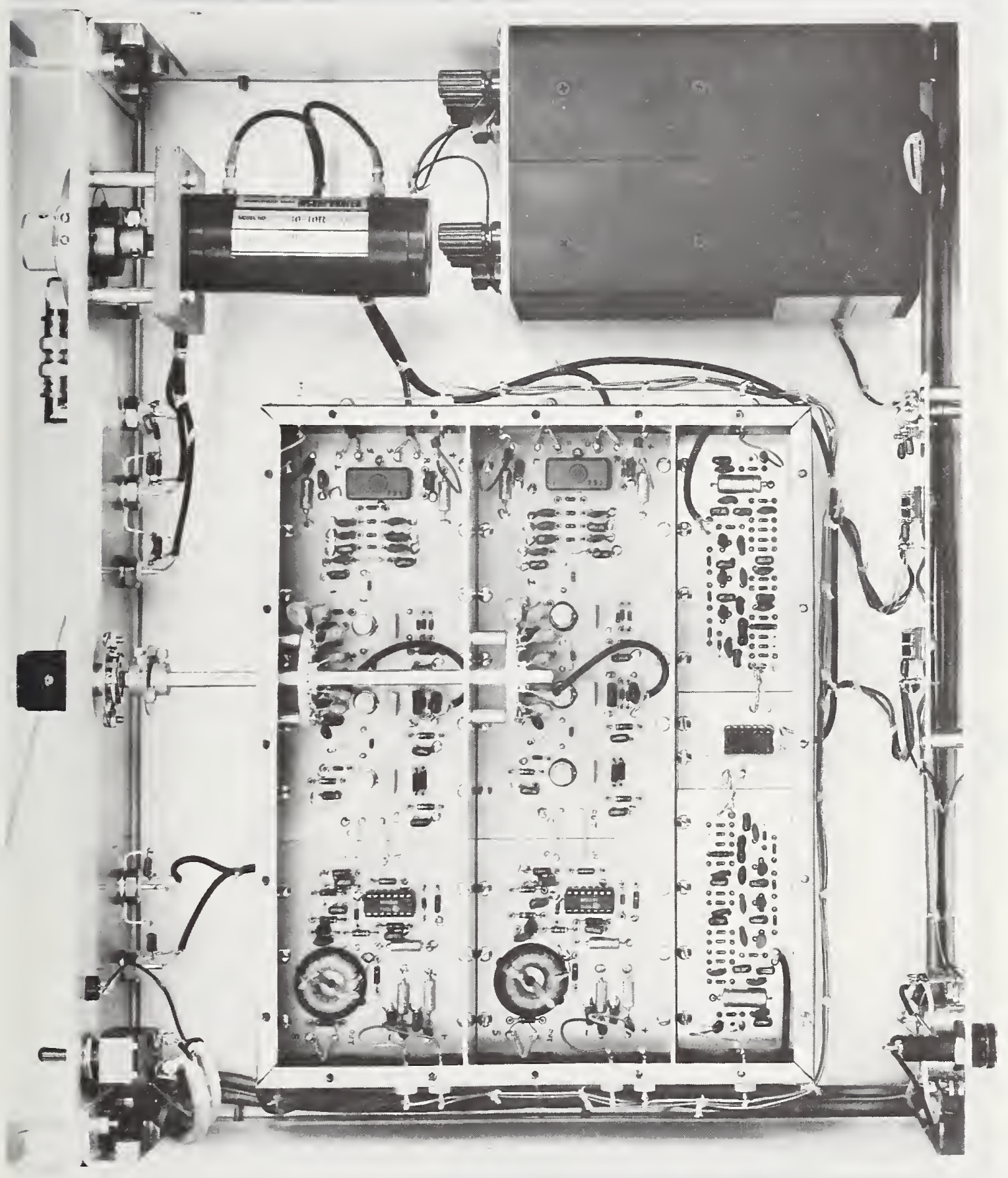




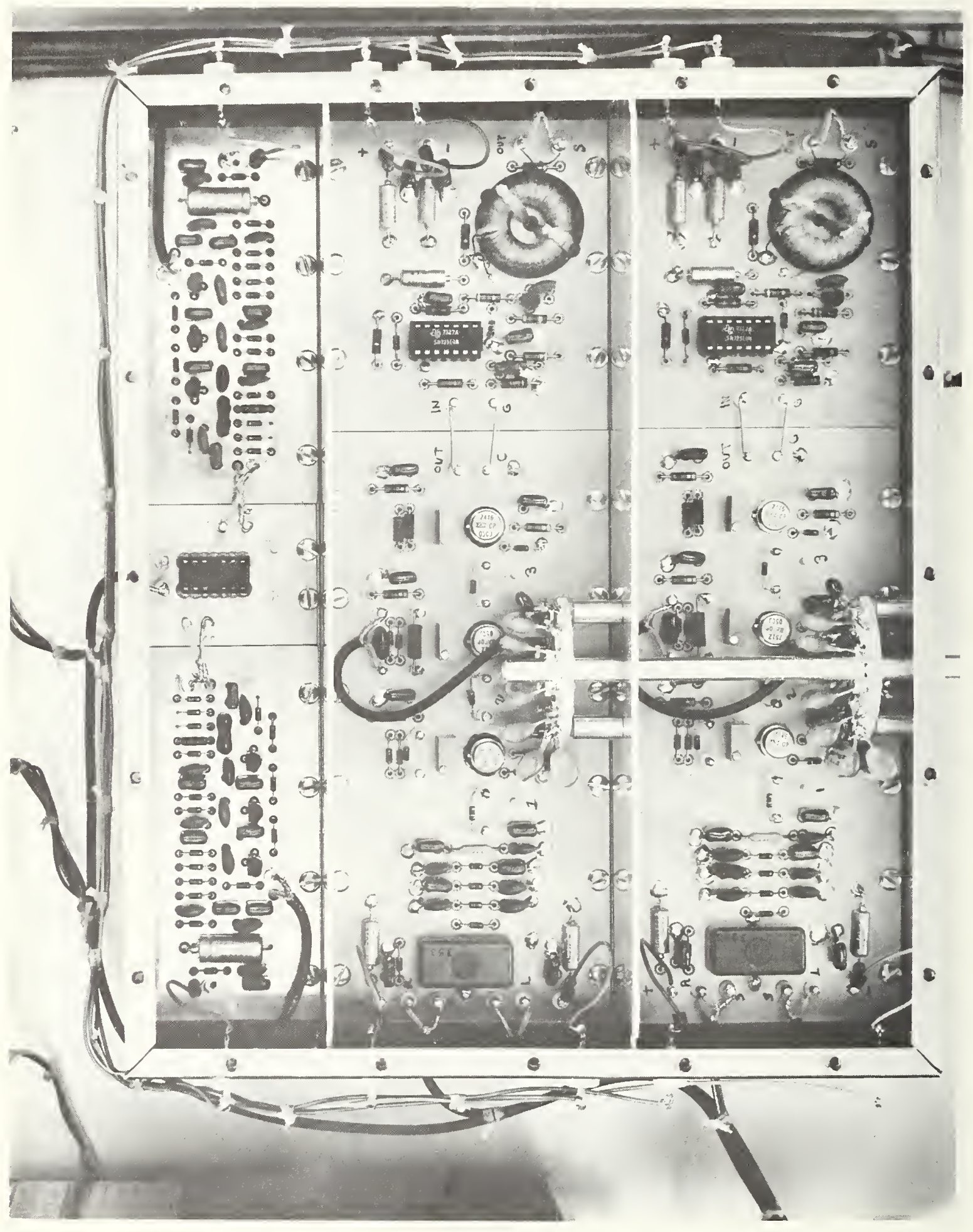


NBS.114A (REV. 7.73)

\begin{tabular}{|c|c|c|c|}
\hline $\begin{array}{l}\text { U.S. DEPT. OF COMM. } \\
\text { BIBLIOGRAPHIC DATA } \\
\text { SHEET }\end{array}$ & $\begin{array}{l}\text { 1. PUBLICATION OR REPORT NO. } \\
\text { NBSIR } 75-827\end{array}$ & $\begin{array}{l}\text { 2. Gov't Accession } \\
\text { No. }\end{array}$ & 3. Recipient's Accession No. \\
\hline \multirow{2}{*}{\multicolumn{3}{|c|}{$\begin{array}{l}\text { 4. TITLE AND SUBTITLE } \\
\text { Report on NBS Dual Mixer Time Difference System (DMTD) } \\
\text { Built for Time-Doma in Measurements Associated with } \\
\text { Phase I of GPS }\end{array}$}} & $\begin{array}{l}\text { 5. Publication Date } \\
\text { January } 1976\end{array}$ \\
\hline & & & $\begin{array}{l}\text { 6. Performing Organization Code } \\
277.04\end{array}$ \\
\hline \multicolumn{3}{|l|}{ 7. DuTHOR(\$) Allan } & $\begin{array}{l}\text { 8. Performing Qrean Report No. } \\
\text { NBSIR } 75-827 \text {. }\end{array}$ \\
\hline \multirow{2}{*}{\multicolumn{3}{|c|}{$\begin{array}{l}\text { 9. PERFORMING ORGANIZATION NAME AND ADDRESS } \\
\text { NATIONAL BUREAU OF STANDARDS } \\
\text { DEPARTMENT OF COMMERCE } \\
\text { WASHINGTON, D.C. } 20234\end{array}$}} & $\begin{array}{l}\text { 10. Project/Task/Work Unit No. } \\
2774246\end{array}$ \\
\hline & & & 11. Contract/Grant No. \\
\hline \multirow{2}{*}{\multicolumn{3}{|c|}{ 12. Sponsoring Organization Name and Complete Address (Street, City, State, ZIP) }} & $\begin{array}{l}\text { 13. Type of Report \& Period } \\
\text { Covered }\end{array}$ \\
\hline & & & 14. Sponsoring Agency Code \\
\hline
\end{tabular}

15. SUPPLEMENTARY NOTES

16. ABSTRACT (A 200-word or less factual summary of most significant information. If document includes a significant bibliography or literature survey, mention it here.)

Based on a previous work reported at the 1975 Frequency Control Symposium, the National Bureau of Standards was asked to build a Dual Mixer Time Difference (DMTD) measuring system. This report includes the design, construction, and testing of this DMTD system in fulfillment of this request. The precision of time difference measurement with this system was shown to be about 0.1 picosecond and the accuracy about 10 ps; similarly, the frequency stability precision was shown to be described by

$\sigma_{y}(\tau) \simeq 10^{-13} \tau^{-1}, 0.1 \mathrm{~s}<\tau<10^{3} \mathrm{~s}$ and equal to $10^{-16}$ at $\tau$ equal about half a day.

The request for this DMTD system was for measuring the clocks that will go on board the satellites for Phase I of the Global Positioning System (GPS) program. The DMTD system described in this report is the only system that can easily meet all of the time-domain measurement requirements for this program.

17. KEY WORDS (six to twelve entries; alphabetical order; capitalize only the first letter of the first key word unless a proper name; separated by semicolons) Frequency measurement; Frequency mixing; Global Positioning System; Isolation amplifiers; Low-noise amplifiers; Precision frequency measurements; Precision time measurements; Time difference measurements; Time-domain frequency stability; Time interval.

18. AVAILABILITY $\bar{x}$ Unlimited

For Official Distribution. Do Not Release to NTIS

Order From Sup. of Doc., U.S. Government Printing Office

Washington, D.C. 20402, SD Cat. No. C13

\begin{tabular}{|l|c|}
\hline $\begin{array}{l}\text { 19. SECURITY CLASS } \\
\text { (THIS REPURT) }\end{array}$ & 21. NO. OF PAGES \\
UNCL ASSIF IED & 20 \\
\hline $\begin{array}{l}\text { 20. SECURITY CLASS } \\
\text { (THIS PAGE) }\end{array}$ & 22. Price \\
UNCLASSIFIED & 3.25 \\
\hline
\end{tabular}

X Order From National Technical Information Service (NTIS) Springfield, Virginia 22151 
